\title{
Cardiac CT confirmation of normal prosthetic mechanical aortic valve function in patient with presyncope and significantly increased Doppler velocities
}

Department of Cardiology, Royal Liverpool and Broadgreen University Hospitals NHS Trust, Liverpool, UK

\section{Correspondence to}

Dr Jamal N Khan, jamal.khan@rlbuht.nhs.uk

Accepted 13 April 2018
Check for updates

To cite: Khan JN, Reigler J, Murray SW, et al. BMJ Case Rep Published Online First: [please include Day Month Year]. doi:10.1136/bcr-2018 225024

\section{DESCRIPTION}

A 37-year-old man presented to our emergency department with unprovoked presyncope, breathlessness and atypical chest pain. His history included a Carbomedics $27 \mathrm{~mm}$ bileaflet mechanical aortic valve replacement (AVR) 18 years prior for endocarditis, severe aortic regurgitation and left ventricular systolic dysfunction (LVSD). A biventricular pacemaker (cardiac resynchronisation therapy with defibrillator (CRT-D)) was implanted 7 years later. Observations, including postural blood pressure, biventricular-paced ECG and bloods including troponin and D-dimer assays, were unremarkable. CRT-D interrogation demonstrated no arrhythmias. Although the international normalised ratio (INR) was satisfactory on admission (2.8), compliance with taking daily warfarin was inconsistent with poor anticoagulation clinic attendance. The time spent in therapeutic INR range was hence only $60 \%$.

Given the above and increasing Doppler AVR velocities on transthoracic echocardiography (TTE) 2 years prior (VMax $2.6 \mathrm{~m} / \mathrm{s}$ (mean

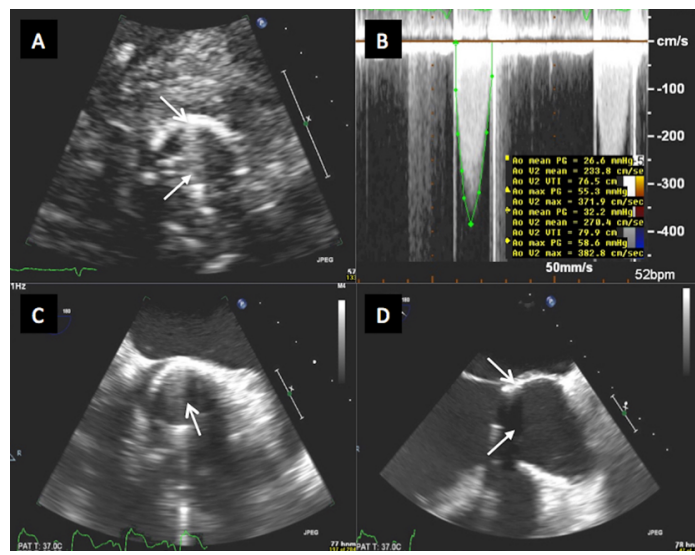

Figure 1 (Echocardiography). Top row (transthoracic echocardiography): (A) Limited visualisation of aortic valve replacement (AVR) (open-headed arrow) with reverberation artefact (closed-headed arrow), (B) continuous-wave (VMax $3.6 \mathrm{~m} / \mathrm{s}$ ) through AVR indicative of high velocities which can indicate valve obstruction. Bottom row (transoesophageal echocardiography): (C) limited visualisation of AVR (open-headed arrow) with reverberation artefact and (D) inability to visualise leaflets and valve orifice due to shielding (ultrasound drop-out) artefact (closed-headed arrow) gradient $26 \mathrm{~mm} \mathrm{Hg}$ ) vs VMax $1.6 \mathrm{~m} / \mathrm{s}$ (mean gradient $7 \mathrm{~mm} \mathrm{Hg}$ ) 8 years ago), TTE was repeated (figure 1A,B). This demonstrated a severely dilated and impaired left ventricle and significantly elevated AVR Doppler velocities (VMax $3.6 \mathrm{~m} / \mathrm{s}$ (mean gradient $28 \mathrm{~mm} \mathrm{Hg}$ ), dimensionless index 0.22 , acceleration time (AT) $130 \mathrm{~ms}$ and AT/ejection time ratio 0.5 ) compared with previous studies and reference values, especially when considering severe LVSD, leading to suspicion of severe AVR obstruction as cause of symptoms. There was no significant aortic regurgitation. However, TTE image

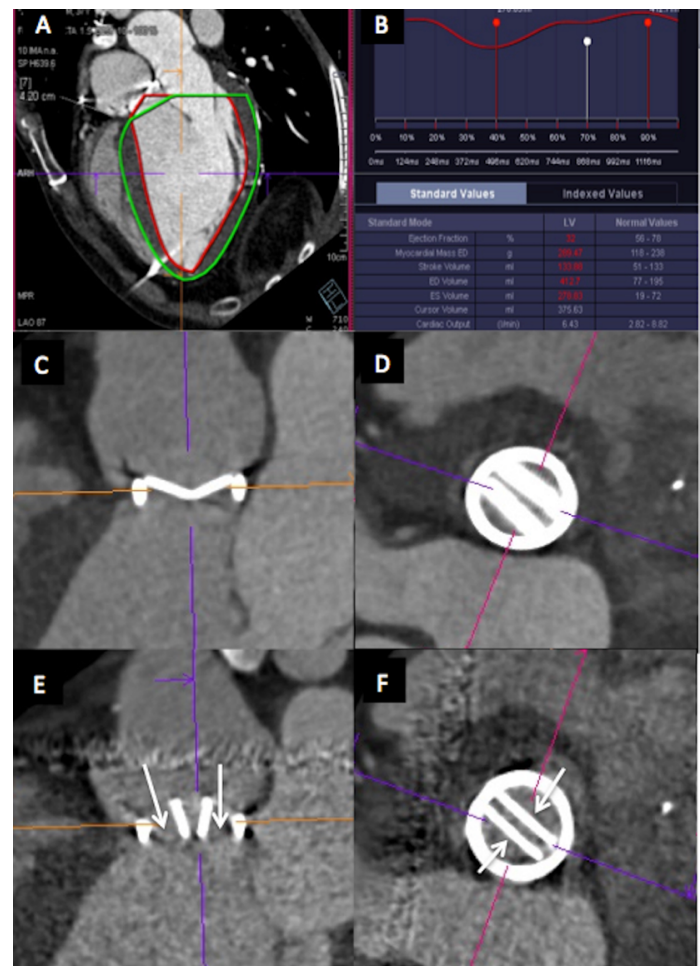

Figure 2 (Multidetector Computed Tomography (MDCT)) (A) Accurate visualisation and assessment of left ventricular (LV) volumetrics and systolic function (red and green contours represent endocardial and epicardial end-diastolic volumes, respectively), (B) resultant LV volumetric data, orthogonal long-axis (C) and short-axis (D) views of bileaflet mechanical aortic valve replacement in closed position, corresponding long-axis (E) and shortaxis $(F)$ views in open position with two resultant orifices (open-headed arrows) confirming unobstructed normal leaflet mobility. 


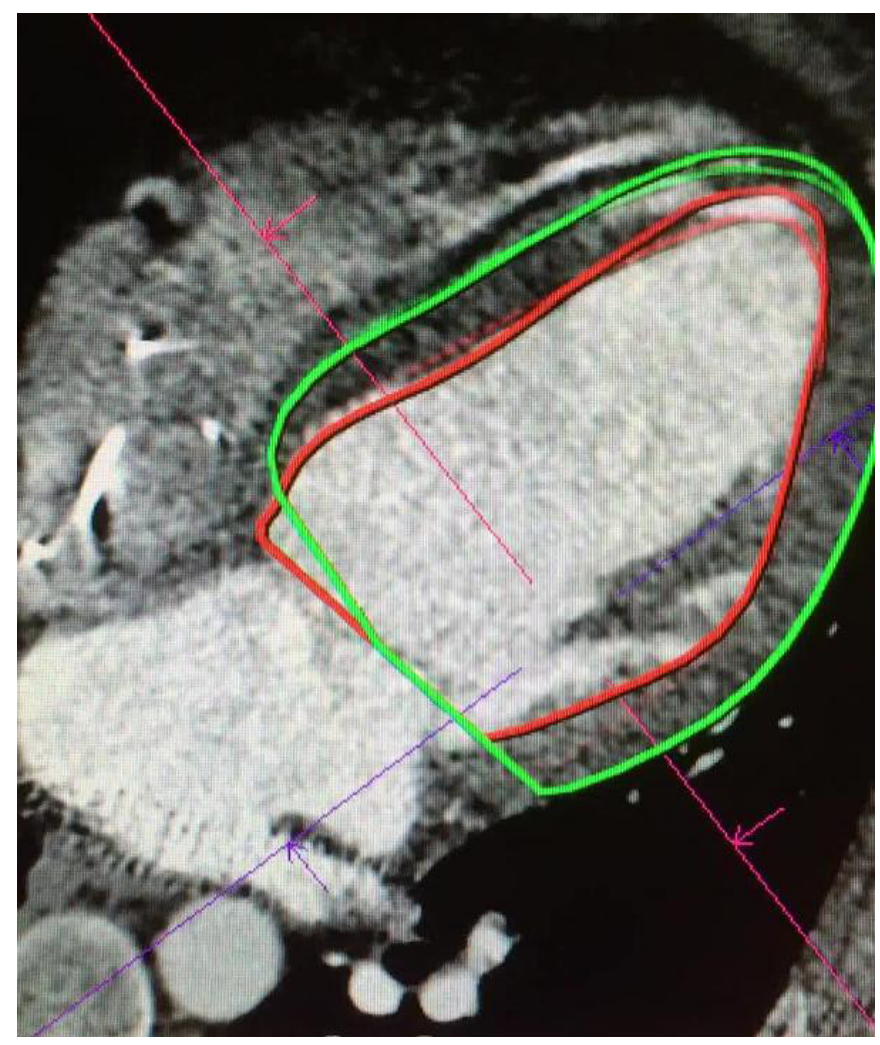

Video 1 Cine of left ventricular contraction demonstrating severely dilated left ventricle with severe global systolic dysfunction, right atrial and right ventricular pacing leads visible.

quality was suboptimal due to echocardiographic windows and AVR reverberation artefact, precluding accurate leaflet assessment. Subsequent transoesophageal echocardiography (TOE) (figure 1C,D) was poorly tolerated. TOE images were degraded by reverberation and shielding artefact, precluding AVR assessment. The patient declined TOE under general anaesthetic and cardiovascular magnetic resonance (CMR) assessment was contraindicated due to CRT implantation.

The mechanism for his elevated AVR velocities was unexplained and given his symptoms, redo AVR surgery and thrombolysis were being discussed based on potential aetiologies of valve pannus/mechanical failure and thrombus, respectively.

He then underwent a retrospectively gated cardiac CT scan (figure 2). Its high spatial and good temporal resolution allowed accurate left ventricular volumetric analysis (figure 2A,B, video 1) confirming the severely dilated and impaired left ventricle, excellent AVR leaflet visualisation confirming the absence of thrombus/pannus with normal, unrestricted leaflet motion (figure 2C-F, video 2) and excluded significant coronary artery disease, aortic pathology and pulmonary emboli.

CT confirmed good AVR function and in conjunction with previous echocardiographic data review confirmed that increased AVR velocities were due to progressively improved left ventricular ejection fraction (LVEF) and stroke volume (SV) and ejection fraction (LVEF) post-CRT (current TTE: left ventricular outflow tract (LVOT) VTI $17 \mathrm{~cm}, \mathrm{SV} 115 \mathrm{~mL}$ vs 2 years ago: LVOT VTI $10 \mathrm{~cm}$, SV $68 \mathrm{~mL}$ vs 8 years ago: LVOT VTI $5.3 \mathrm{~cm}$, SV $52 \mathrm{~mL})$. Doppler values were higher than reference due to high SV (134 mL) despite severe LVSD (LVEF 32\%), due to severe left ventricular dilatation (end-diastolic volume $413 \mathrm{~mL}$ ). Cardiac CT was the only modality accurately assessing the AVR and left ventricle and prevented potential inappropriate

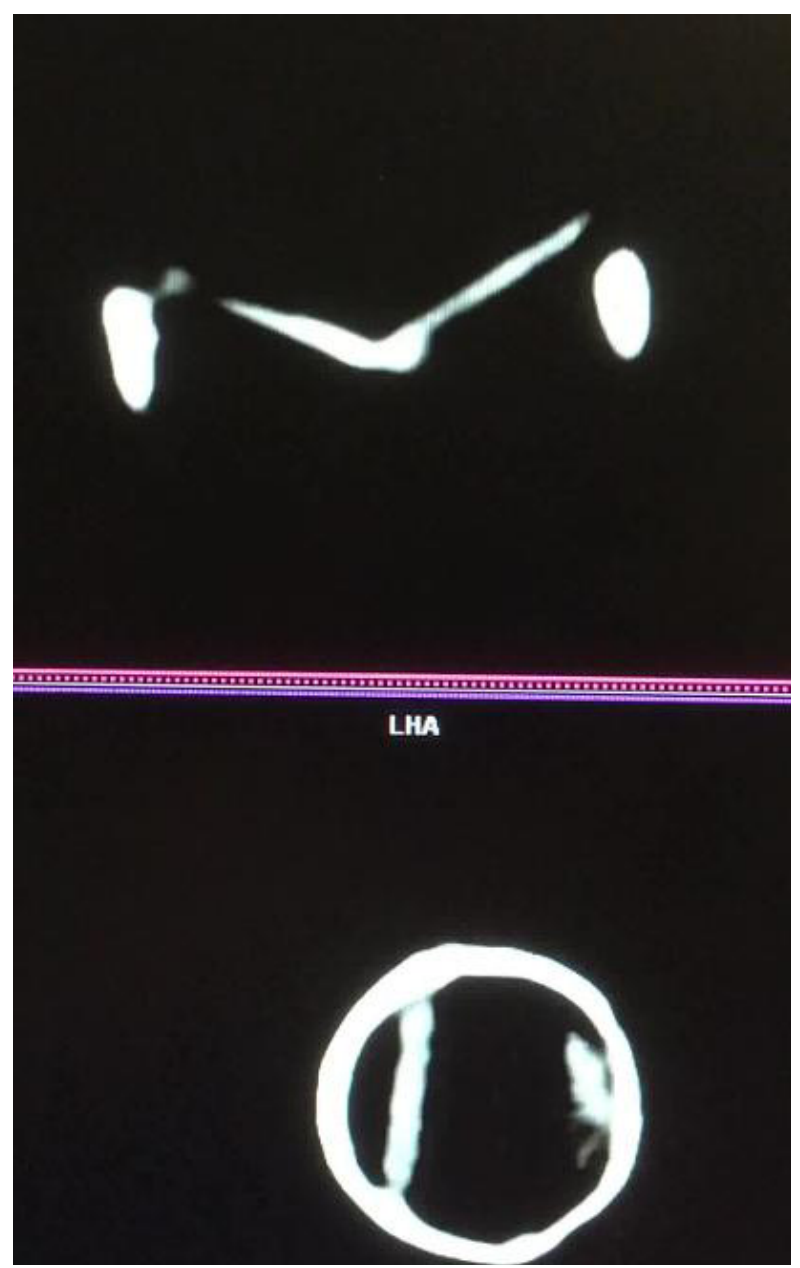

Video 2 Cine demonstrating normal leaflet mobility (corresponding video to figure 2).

consideration of redo AVR or thrombolysis. Cardiac pathology was excluded as a cause of symptoms, which were attributed to long-standing anxiety and panic attacks.

Mechanical valve imaging using echocardiography can be limited by reverberation (reflective) and shielding (signal loss) artefacts. This can significantly degrade visualisation of leaflets and valve housing. ${ }^{12} \mathrm{X}$-ray fluoroscopy can demonstrate leaflet mobility but is limited by its angle dependence and inability to accurately visualise pannus and thrombus. Cardiac CT allows excellent non-invasive assessment of prosthetic valves due to high spatial resolution and excellent visualisation of leaflet motion. ${ }^{1}{ }^{2}$ CT attenuation characteristics (Hounsfield units) differ according to material composition, allowing distinction between the key differentials of valve obstruction: thrombus and pannus, which can be notoriously challenging using echocardiography, X-ray fluoroscopy and CMR.$^{1-3} \mathrm{CT}$ also provides valuable left ventricular volumetric/functional data and coronary

\section{Patient's perspective}

'Because of the CT scan, the doctors could work out how well my valve was working. This meant I didn't need another operation or more tests, especially the camera test (TOE)'

Signed consent form attached (completed/signed by patient on Thu 1 Mar 2018) 


\section{Learning points}

- Imaging of mechanical cardiac valves using echocardiography can be significantly limited by reverberation and shielding artefacts, degrading leaflet assessment.

- Pannus and thrombus are key differentials for mechanical valve obstruction and can be challenging to assess on echocardiography, X-ray fluoroscopy and cardiovascular magnetic resonance.

- Cardiac CT allows accurate non-invasive assessment of prosthetic valves with high spatial resolution. It allows excellent assessment of leaflet mobility, assessment for pannus and thrombus, visualisation of complications arising from endocarditis (abscesses and dehiscence) and also permits left ventricular and coronary artery assessment within the same study.

artery, aorta and pulmonary arterial imaging within the same sitting. Cardiac CT is a valuable and currently underused tool in the multimodality imaging assessment of prosthetic cardiac valves, despite its widespread availability.

Acknowledgements We would like to acknowledge the echocardiography and cardiac CT departments at The Royal Liverpool University Hospital, in particular Sue Alderton and Brian Devlin for helping perform the TOE and CT respectively.
Contributors All authors were heavily involved in the production of the manuscript and images/movies, and then finalising approval of the version published. All authors are agreeable to be accountable for the article and to ensure that all questions regarding the accuracy or integrity of the article are investigated and resolved. JNK: planning, conception and production of manuscript/figures/videos. Undertook clinical care, imaging of patient (transthoracic echocardiography (TTE), transoesophageal echocardiography (TOE), cardiac CT) and interpretation of data. JR: review and editing of manuscript/figures/videos. Undertook imaging of patient (TTE) and interpretation of data. SWM and BR: review and editing of manuscript/figures/videos. Undertook clinical care and imaging of patient (cardiac CT) and interpretation of data.

Funding The authors have not declared a specific grant for this research from any funding agency in the public, commercial or not-for-profit sectors.

Competing interests None declared.

Patient consent Obtained.

Provenance and peer review Not commissioned; externally peer reviewed.

(c) BMJ Publishing Group Ltd (unless otherwise stated in the text of the article) 2018. All rights reserved. No commercial use is permitted unless otherwise expressly granted.

\section{REFERENCES}

1 Moss AJ, Dweck MR, Dreisbach JG, et al. Complementary role of cardiac CT in the assessment of aortic valve replacement dysfunction. Open Heart 2016;3:e000494.

2 Tsai WL, Tsai IC, Chen MC, et al. Comprehensive evaluation of patients with suspected prosthetic heart valve disorders using MDCT. AJR Am J Roentgenol 2011;196:353-60.

3 Tanis W, Habets J, van den Brink RB, et al. Differentiation of thrombus from pannus as the cause of acquired mechanical prosthetic heart valve obstruction by non-invasive imaging: a review of the literature. Eur Heart J Cardiovasc Imaging 2014;15:119-29.

Copyright 2018 BMJ Publishing Group. All rights reserved. For permission to reuse any of this content visit http://group.bmj.com/group/rights-licensing/permissions.

BMJ Case Report Fellows may re-use this article for personal use and teaching without any further permission.

Become a Fellow of BMJ Case Reports today and you can:

- Submit as many cases as you like

- Enjoy fast sympathetic peer review and rapid publication of accepted articles

- Access all the published articles

- Re-use any of the published material for personal use and teaching without further permission

For information on Institutional Fellowships contact consortiasales@bmjgroup.com

Visit casereports.bmj.com for more articles like this and to become a Fellow 